Chapman University

Chapman University Digital Commons

Education Faculty Articles and Research

College of Educational Studies

$1-7-2016$

\title{
Adult Relationships in Multiple Contexts and Associations with Adolescent Mental Health
}

\author{
Gordon Capp \\ University of Southern California \\ Ruth Berkowitz \\ Ben-Gurion University of the Negev \\ Kate Sullivan \\ University of Southern California \\ Ron Avi Astor \\ University of Southern California
}

Kris T. De Pedro

Chapman University, depedro@chapman.edu

See next page for additional authors

Follow this and additional works at: http://digitalcommons.chapman.edu/education_articles

Part of the Child Psychology Commons, Developmental Psychology Commons, Educational Assessment, Evaluation, and Research Commons, Educational Psychology Commons, Other Mental and Social Health Commons, Personality and Social Contexts Commons, and the Social Psychology and Interaction Commons

\section{Recommended Citation}

Capp, G., Berkowitz, R., Sullivan, K., Astor, R. A., Pedro, K. D., Gilreath, T. D., ... Rice, E. (2016). Adult Relationships in Multiple Contexts and Associations With Adolescent Mental Health. Research on Social Work Practice, 1049731515624967. http://doi.org/ $10.1177 / 1049731515624967$ 


\section{Adult Relationships in Multiple Contexts and Associations with Adolescent Mental Health}

\section{Comments}

This is a pre-copy-editing, author-produced PDF of an article accepted for publication in Research on Social Work Practice in 2016. Changes may have occurred following peer review. This version of the paper was presented at the SSWR 2015 National Conference. The definitive publisher-authenticated version is available online at DOI: $10.1177 / 1049731515624967$.

\section{Copyright}

The authors

\section{Authors}

Gordon Capp, Ruth Berkowitz, Kate Sullivan, Ron Avi Astor, Kris T. De Pedro, Tamika D. Gilreath, and Eric Rice 
Adult Relationships in Multiple Contexts and Associations with Adolescent Mental Health

Paper presented at SSWR 2015 National Conference

Gordon Capp, MSW, LCSW

Doctoral Student

University of Southern California School of Social Work

Montgomery Ross Fisher Building

669 West $34^{\text {th }}$ Street

Los Angeles, CA 90089

Ruth Berkowitz, Ph.D.

Ben-Gurion University of the Negev

Beer-Sheva

Israel

Kate Sullivan, MSW

Doctoral Student

University of Southern California School of Social Work

Montgomery Ross Fisher Building

669 West $34^{\text {th }}$ Street

Los Angeles, CA 90089

Ron Avi Astor, Ph.D.

Professor

University of Southern California School of Social Work

Montgomery Ross Fisher Building

669 West $34^{\text {th }}$ Street

Los Angeles, CA 90089

Kris De Pedro, Ph.D.

Assistant Professor

College of Educational Studies

Chapman University

One University Drive

Orange, CA 92866

Tamika D. Gilreath, Ph.D.

Assistant Professor

University of Southern California School of Social Work

Montgomery Ross Fisher Building

669 West $34^{\text {th }}$ Street

Los Angeles, CA 90089 


\author{
Eric Rice, Ph.D. \\ Assistant Professor \\ University of Southern California School of Social Work \\ Montgomery Ross Fisher Building \\ 669 West $34^{\text {th }}$ Street \\ Los Angeles, CA 90089
}




\begin{abstract}
Many factors influence the experiences of adolescents as they navigate various social contexts. Adult relationships are critical support for adolescents because of their potential to foster positive development and provide protective influences. However, few studies examine multiple ecological layers of adult relationships in connection with well-being and depression. This study examines the influence of relationships from multiple contexts for adolescents and their mental health. Using the 2011 California Healthy Kids Survey (CHKS), a sample of 7 th, $9^{\text {th }}$, and $11^{\text {th }}$ grade students $(\mathrm{n}=14,931)$ was drawn from eight school districts in Southern California. Approximately half of the sample was female, and approximately half Latino. Separate multivariate OLS regression models were conducted for well-being and depression. For well-being, the model examining adult support explained $21.5 \%$ of the variance. Parent, teacher, and community adult support were all significantly positively associated with wellbeing. For depression, the model examining adult support explained only $5.3 \%$ of the variance. Parent, teacher, and community adult support were all significantly negatively associated with depression. Of particular interest is that more variance in well-being than depression is explained by social support, indicating that adult support may be more important for supporting well-being than for alleviating depression. This study also provides support for the belief that combinations of multiple adult relationships are important; parent, teacher, and community adult support were all independently significant in models explaining well-being and depression.
\end{abstract}




\section{Adult Social Support and Ecological Context}

Myriad factors influence the experiences of adolescent youth in their schools and communities. Obstacles to healthy development and academic progress for students include learning difficulties, behavior problems, and mental health issues (Lean \& Colucci, 2010, 2013; Richman, Bowen, \& Woolley, 2004). These factors all have consequences for academic outcomes, relationships with parents and caregivers, and future success in work and relationships. Adult relationships are particularly important for adolescents because of their ability to be protective and facilitate development, or to be a risk factor and potentially lead to increased problems (Astor, De Pedro, Gilreath, Esqueda, \& Benbenishty, 2013; Jennings, \& Greenberg, 2009; Sesma, Mannes, \& Scales, 2013; Young \& Leadbeater, 2010).

Research on the contextual nature of these relationships is needed. Researchers have suggested increased focus on context (Astor et al., 2013; Jennings \& Greenberg, 2009) and the influences of family and non-family relationships on adolescent development (Darling et al. 2003; Yeung \& Leadbeater, 2010). For adolescents, then, research about supportive adult relationships needs to include multiple domains of their experience, including home, school, and community or other adult relationships (Darling, Hamilton, \& Shaver, 2003). The purpose of this study is to examine the relationship between adolescents' relationships with adults in various ecological contexts and their mental health.

Particularly important to this study is the belief that adult relationships are critical assets for youth, and that these assets include relationships with parents and family, teachers, and other adults (Benson, 2003; Sesma et al., 2013). These assets can be understood as part of a larger framework of risk and protective factors that encompasses both environmental and intrapersonal influences on adolescents' educational and health outcomes (Benson, 2003). Adult relationships 
can be understood as supportive environmental factors that empower youth and provide a sense of value and belonging (Edwards et al., 2007; Jarrett et al., 2005). Social connections outside of the family may also provide positive opportunities or contribute to social isolation within communities (Arthur et al., 2007). Beyond risk and protective factors, these examples of supportive adult relationships emphasize the importance and utility of social support. Social support theory proposes that social support reduces the effects of stressors on health, and that support promotes coping, and therefore health and well-being (Lakey \& Cohen, 2000). The current focus on depression and well-being aligns with social support theory, as we believe adult relationships can restore adolescent health and protect against future stressors.

As relationships with adults comprise needed social support for adolescents, it is also clear that influences come from multiple contexts, including family members, teachers, and adults in the community (Astor et al., 2013; Darling et al., 2003; Sallis, Owen, \& Fisher, 2008; Youngblade et al., 2007). Examining adult relationships at multiple ecological layers is therefore important and may help clarify how various categories of support influence a particular individual's mental health. For example, Scales et al. (2006) argue that a student's success at school is the result of a "complex interplay" between levels of his or her ecology; caring and supportive relationships, student motivation, and strong social norms and expectations are just some of the ecological levels involved.

\section{Parent Relationships}

Parents clearly represent a principal ecological layer of importance and support for children. Beyond the intuitive salience of parents as caregivers, research in multiple areas has relevance for the current examination of adult support. In a study that sought to compare the influences of parents to other groups, Greenberg, Siegel, and Leitch (1983) found that the quality 
of attachment to parents was more powerful than that of peers in predicting well-being. In another study examining significant influences in their lives, adolescents chose a parent as the most significant relative (Tatar, 1998). Research has also demonstrated that parent support is protective for students experiencing stressful situations (e.g. victimization) and helps protect against emotional problems (Yeung \& Leadbeater, 2010). Many examples illustrate the importance of parents in building social capital and helping to build resilience in youth (Furstenburg \& Hughes, 1995; Pong, Hao, \& Garnder, 2005; Sesma, Mannes, \& Scales, 2013). Finally, there is evidence that parent involvement is an important element of school success for youth (Jeynes, 2007; Smith, Wohlstetter, Kuzin, \& De Pedro, 2011; Zellman \& Waterman, 1998). It is possible that students perceive involvement as a form of support. That several of these studies examined parents and teachers together stresses the importance of understanding support coming from overlapping spheres of influence.

\section{Teacher Relationships}

Supportive school climates can protect against psychological and social risk factors (Bond et al., 2007; Thapa et al., 2013). In contrast, students who have non-supportive relationships with peers and teachers have worse outcomes related to substance use, mental health symptoms and academic outcomes (Bond et al., 2007; Jennings \& Greenberg, 2009; Thapa et al., 2013). School is clearly an important ecological layer for students, and teachers are a prominent source of support for students who face many challenges in the course of their academic careers. Jennings and Greenberg (2009) emphasize the importance of teachers as rolemodels who provide support. When students have relationships with adults that are trusting, responsive and promote social and emotional development, they internalize healthy models of functioning (Jennings \& Greenberg, 2009). 
Baker (1999) noted that teachers might be particularly important influences in helping students acclimate to a school and provide a pathway for students to access other supportive elements of school climate. In a study seeking to understand how people characterize significant individuals, teachers were often identified as significant non-family adults, and as role models (Tatar, 1998). Especially for secondary students, the amount of time they spend at schools allows for increased interaction with and support from teachers (Yeung \& Leadbeater, 2010). Finally, Murray and Greenberg (2000) examined children's social experiences in schools and concluded that positive connection to teachers may influence children's ability to approach new situations and challenges. The continued study of teacher and adult relationships is needed to examine how contextual factors affect students with various mental health and social emotional needs (Astor et al., 2013).

\section{Community Adult Relationships}

While much research about adolescent social experiences focus on parents and peers, less is known about the unique contributions of unrelated adults (Darling et al., 2003). Darling et al. (2003) go as far as calling unrelated adults "the neglected other" and argue that we need to better understand the ways that adults outside of the family impact adolescents. Some have focused on examining the roles of mentors (Darling et al., 2003; Hamilton \& Hamilton, 2004), and while these relationships are important, less formal or defined relationships are important as well. Scales et al. (2006) write that more adults need to actively contribute to the positive development of youth in their various communities. These adults and mentors could conceivably include coaches, employers, after school program staff, church leaders, and others.

As adolescents develop, relationships with adults have multiple facets. Support from other adults in the lives of youth helps provide emotional support, alternative role models, and 
social capital regarding connections for opportunities like jobs or internships (Hamilton \& Hamilton, 2004). Relationships with people in the community are also needed for making a successful transition from adolescence to adulthood and for youth to feel like they can contribute to a larger community (Edwards et al., 2007; Jarrett, Sullivan, \& Watkins, 2005).

\section{Current Study}

There appear to be few studies that examine multiple ecological layers of adult relationships in connection with well-being and depression. As such, this study aspires to add to our knowledge about the influence of relationships from multiple contexts in the lives of adolescents and how this impacts mental health. It is hoped this information can inform efforts to enhance social support for adolescents.

The independent variables will include adolescent perceptions of three categories of adult relationships: parents/family, teachers, and other adults in the community. Gender, ethnicity, and grade level will also be examined as these characteristics are likely to influence their perceptions of adult relationships in their lives. The dependent variables are two scales measuring well-being and depression. It is hypothesized that in general, higher levels of perceived support will result in higher levels of well-being and lower levels of depression.

\section{Methods}

\section{Sample}

This study is a secondary analysis of quantitative data available through the "Building Capacity in Military Connected Schools" Project. The Building Capacity Project is a collaboration between the University of Southern California (USC), the Department of Defense Education Activity (DoDEA), and a consortium of 8 school districts in San Diego County. The Building Capacity team uses the California Healthy Kids Survey (CHKS) to monitor progress in 
consortium schools, and developed a Military-Connected Schools Supplemental Module to gather data specific to military-connected students and families. This module is used by schools in the Building Capacity consortium, and is available statewide.

The CHKS is administered biennially in schools to $5^{\text {th }}, 7^{\text {th }}, 9^{\text {th }}$, and $11^{\text {th }}$ grade students throughout the state of California (Hanson \& Kim, 2007). Students in attendance on the day of administration complete surveys; this information therefore indicates self-reported perceptions of students (Hanson \& Kim, 2007). Data for these analyses are from the March 2011 administration of the CHKS. In 2011, the CHKS survey, including the military module, was administered to 14 , 633 students, which represents a response rate of $86.5 \%$ (Gilreath et al., 2013).

\section{Measures}

\section{Dependent Variables}

Well-being. To assess well-being, participants were asked six questions. These questions began: "In the last 30 days, how often did you feel..." Specific items included: feel full of energy; happy; proud; good about life; excited; strong. Possible responses to these items were on a five-point Likert scale that included: $1=$ None of the time; $2=$ A little of the time; $3=$ Some of the time; $4=$ Most of the time; and $5=$ all of the time. This scale was adapted from the Positive and Negative Affect Schedule - Expanded Form (Watson \& Clark. 1999). A well-being score was calculated for each respondent by summing up the six items and creating an average score for well-being. Scores range from 1-5, where higher scores indicate higher levels of well-being. Other researchers using this adapted scale have reported an internal reliability of $\alpha=.894$ (Cederbaum et al., 2013; De Pedro et al., 2013).

Depression. Participants were also asked six questions to assess depression. These questions began, "In the last 30 days, how often did you feel..." Specific items included: like 
everything feels hard to do; nothing can cheer you up; restless; cannot stay still in one place; nervous; do not have much hope. Possible responses to these questions were also on a five-point Likert scale and included: $1=$ None of the time; $2=$ A little of the time; $3=$ Some of the time; 4 $=$ Most of the time; and $5=$ all of the time. A depression score was calculated for each respondent by summing and creating an average score ranging from 1-5. Higher scores indicate higher levels of depression. These questions were adapted from the Kessler 6 scale (Kessler et al., 2002). Similarly, researchers using this adapted scale report an internal reliability of $\alpha=.848$ (Cederbaum et al., 2013; De Pedro, 2013). The depression variable was found to have high positive skew and so a logarithmic transformation was performed on depression to reduce skewness. In addition, the correlation between well-being and depression was examined and this yielded a significant $(\mathrm{p}=.01)$ negative correlation $\mathrm{a}=-.159$. This indicates that well-being and depression are likely separate constructs and not opposite ends of a continuum.

\section{Independent Variables}

Demographic variables. Demographic independent variables included gender, grade (seventh, ninth and eleventh), and race/ethnicity African American, Hispanic, White, mixed race and other). All demographic variables were dummy coded for use in the regression model.

Teacher relationships. Participants were asked about their relationships with teachers. This construct included six items: At my school, there is a teacher who really cares about me; who tells me when I do a good job; who notices when I'm not there; who wants me to do my best; who listens to me when I have something to say; who believes I will be a success. Responses to these items were on a four-point Likert scale and included: $1=$ Not at all; $2=\mathrm{A}$ little true; 3 = Pretty much true; and 4 = Very much true. A composite score was calculated for 
each respondent by summing these items and dividing by six. Responses range from 1-4, with higher numbers indicating more perceived support.

Community adult relationships. Participants were also asked about their relationships with adults in the community, outside of school. This construct also included six items with the same four-point Likert scale as teacher relationships where possible responses included: $1=$ Not at all; 2 = A little true; 3 = Pretty much true; and $4=$ Very much true. These items included: An adult outside of home or school really cares about me; tells me when I do a good job; notices when I am upset about something; believes that I will be a success; always wants me to do my best; I trust an adult outside of home or school. Summing these six items and dividing by six again calculated a composite score, so that responses range from 1-4, with higher numbers indicating more perceived support.

Parent relationships. Students' relationships with parents were represented with two separate items in the CHKS survey. The first item, My parents help me with school work, was measured with a four item Likert scale ranging from : $1=$ Not at all; $2=$ A little true; $3=$ Pretty much true; and 4 = Very much true. Higher scores on these items for individuals indicate more perceived support. The second parent support item, My parents come to school to meet the teachers or to attend events, was also measured with the same four-item Likert scale where possible responses included: $1=$ Not at all; $2=$ A little true; $3=$ Pretty much true; and $4=$ Very much true. For both parent support questions, respondents that responded "do not know" were excluded to facilitate multiple regression analysis.

\section{Analysis}

SAS version 9.3 was used to run two separate multivariate ordinary least squared (OLS) regression models to examine associations with well-being and depression. Except for dummy 
coded demographic variables, all independent and dependent variables were examined for normality. An examination of residuals for normality, independence and heteroscedasticity revealed no problems needing transformation. Additionally, tests for multicolinearity indicated no significant problems. The independent variables reflect an ecologically based assumption that influences from multiple ecological layers would influence students' mental health (Benbenishty \& Astor, 2005; Darling et al., 2003; Drukker, Buka, Kaplan, McKenzie \& Van Os, 2005). Parameter estimates from this model are presented in the results section.

\section{Results}

The final sample for these analyses included 14,633 middle and high school students in Southern California (see Table 1). A slight majority (51.6\%) was female. Students were relatively evenly distributed across grade levels, with approximately one-third in seventh, ninth and eleventh grades. Nearly half of the sample reported being Hispanic, followed by White students, those reporting mixed race, and other. African Americans were the smallest group $(2.96 \%)$ in the sample.

Mental health for this sample was characterized by well-being and depression. Both scales are self-reported, and capture the 30 days prior to filling out the questionnaire. The mean score for well-being was 3.44 out of $5(\mathrm{sd}=.94)$; for depression the mean score was 2.28 out of 5 $(\mathrm{sd}=.88)$. Adult support is also self-reported, and three groups of adults are assessed in this paper. The mean score for teacher support was 2.95 out of $4(\mathrm{sd}=.76)$, and for community adult support the mean was 3.32 out of $4(.85)$. Students reported a mean score of 2.33 out of $4(\mathrm{sd}=$ 1.76) about parents coming to school, and a mean score of 2.2 out of $4(\mathrm{sd}=1.11)$ that their parents help with schoolwork. 
Table 1

Overall Sample Characteristics

\begin{tabular}{lcc}
\hline Gender & $\mathrm{N}$ & $(\%)$ \\
$\quad$ Female & & \\
Male & 7548 & $(51.6)$ \\
Grade & 7085 & $(48.4)$ \\
7 & & \\
9 & 4673 & $(31.8)$ \\
11 & 5078 & $(34.5)$ \\
Race/Ethnicity & 4936 & $(33.5)$ \\
African American & & \\
Hispanic & 429 & $(2.96)$ \\
White & 7174 & $(49.5)$ \\
Mixed Race & 3972 & $(27.4)$ \\
Other & 1679 & $(11.6)$ \\
& 1250 & $(8.6)$ \\
Mental Health & & \\
Well-Being & M & $\mathbf{( S D )}$ \\
Depression & 3.44 & $(.94)$ \\
Adult Support & 2.28 & $(.88)$ \\
Teacher Support & & \\
Community Adult Support & & \\
My Parents come to school & 2.95 & $(.76)$ \\
My Parents help with school work & 2.2 & $(1.11)$ \\
\hline
\end{tabular}

Well-being. The results of the multivariate OLS regressions are presented in Table 2. This model was significant overall $(\mathrm{F}[11,11727]=292.43, \mathrm{p}<.0001)$, and explained $21.5 \%$ of the variance $\left(\mathrm{R}^{2}=.2153\right)$ in well-being for students in our sample. Controlling for all other variables, males were positively associated with an increase in well-being $(p<.001)$. Being in $9^{\text {th }}$ and $11^{\text {th }}$ grades was significantly negatively associated with an increase in well-being $(\mathrm{p}<.001)$. Of the various ethnicities represented in the sample, only Latino students showed a significant, positive association with an increase in well-being $(\mathrm{p}<.01)$. Finally, all of the social support 
variables were significant in this model. Parents helping with school work was associated with an increase in well-being $(\mathrm{p}<.001)$ as was parents coming to school to meet with teachers or attend events $(\mathrm{p}<.001)$. Teacher support was associated with an increase in well-being $(\mathrm{p}<$ $.001)$, as was community adult support $(\mathrm{p}<.001)$.

Table 2

Multivariate Results for Model 1: Well-being

\section{Demographic Variables}

Male $^{\mathrm{a}}$

Grade $9^{\mathrm{a}}$

Grade $11^{\mathrm{a}}$

Other

African American

Mixed

Latino

\begin{tabular}{ccc}
$\mathrm{b}$ & $\mathrm{SE}$ & $\mathrm{B}$ \\
\hline $0.19 * * *$ & 0.015 & 0.10 \\
$-0.09 * * *$ & 0.019 & -0.045 \\
$-0.09 * * *$ & 0.020 & -0.048 \\
0.02 & 0.029 & 0.006 \\
0.03 & 0.047 & 0.005 \\
0.003 & 0.026 & 0.001 \\
$0.05 * *$ & 0.018 & 0.027
\end{tabular}

\section{Social Support}

Parents Help with School Work

$0.12 * * * \quad 0.008$

0.145

Parents Come to School

$0.08 * * * \quad 0.007$

0.101

Teacher Support

$0.24 * * * \quad 0.011$

0.197

Community Adult Support

$0.23 * * * \quad 0.010$

0.207

\begin{tabular}{lc}
$\mathbf{R}^{2}$ & .215 \\
\hline $\mathbf{F}$ & 292.43 \\
\hline
\end{tabular}

$* \mathrm{p}<.05 * * \mathrm{p}<.01 * * * \mathrm{p}<.001$

${ }^{\text {a }}$ females and $7^{\text {th }}$ grade students are reference categories

AI, American Indian; PI, Pacific Islander; AN, Alaska Native

Depression. The results of the multivariate OLS regressions are presented in Table 3. This model was also significant $(\mathrm{F}[11,11691]=59.08, \mathrm{p}<.0001)$, and explained $5.3 \%\left(\mathrm{R}^{2}=\right.$ 0.0527) of the variance in depression for this sample. Controlling for all other variables, being male was significantly negatively associated with an increase depression $(\mathrm{p}<.0001)$. Similar to the results for well-being, being in $9^{\text {th }}$ or $11^{\text {th }}$ grade was significantly positively associated with 
an increase in depression ( $\mathrm{p}<.0001$ for both). Students reporting Asian/AI/PI/AN $(\mathrm{p}<.0001)$ as their race and those reporting mixed race $(p<.001)$ were significantly associated with an increase in depression. Again, all social support variables were significant. Having parents who help with school work was significantly negatively associated with increased depression $(\mathrm{p}<$ .001 ), and having parents who come to school to meet with teachers or for events was also significantly negatively associated with an increase in depression $(p<.0001)$. Teacher support was significantly negatively associated with an increase in depression $(\mathrm{p}<.0001)$ as was community adult support $(\mathrm{p}<.0001)$.

Table 3

Multivariate Results for Model 2: Depression

\section{Demographic Variables}

Male $^{\mathrm{a}}$

Grade $9^{\mathrm{a}}$

Grade $11^{\mathrm{a}}$

Other

African American

Mixed

Latino

\begin{tabular}{ccc}
$\mathrm{b}$ & $\mathrm{SE}$ & $\mathrm{B}$ \\
\hline$-0.03 * * *$ & 0.003 & -0.078 \\
$0.01 * * *$ & 0.004 & 0.044 \\
$0.02 * * *$ & 0.004 & 0.070 \\
$0.03 * * *$ & 0.006 & 0.044 \\
-0.0002 & 0.009 & -0.0002 \\
$0.02 * *$ & 0.005 & 0.031 \\
0.003 & 0.003 & 0.010
\end{tabular}

\section{Social Support}

Parents Help with School Work

$\begin{array}{ccc}-0.01 * * & 0.002 & -0.039 \\ -0.01 * * * & 0.001 & -0.049 \\ -0.02 * * * & 0.002 & -0.109 \\ -0.02 * * * & 0.002 & -0.081\end{array}$

\begin{tabular}{lc}
$\mathbf{R}^{2}$ & .053 \\
\hline $\mathbf{F}$ & 59.08 \\
\hline
\end{tabular}

$* \mathrm{p}<.05 * * \mathrm{p}<.01 * * * \mathrm{p}<.001$

${ }^{\mathrm{a}}$ females and $7^{\text {th }}$ grade students are reference categories AI, American Indian; PI, Pacific Islander; AN, Alaska Native 


\section{Discussion}

Perhaps the most important finding in this study is the discrepancy between the variance explained by the social support variables (i.e. parents, teachers, and community adults) for wellbeing compared to depression. This may indicate that these relationships have a greater potential to bolster and maintain well-being than to alleviate depression. Therefore, continued efforts to strengthen supportive relationship and provide opportunities for their development are important. Scales et al. (2011) recently described an emerging area of research focused on "adolescent thriving" rather than risks and challenges. These results offer some support for this endeavor. That adult support explained less variance for depression in this study lends weight to concerns about the presence of mental health issues in schools, including the high prevalence of mental health problems and a significant need for treatment (e.g. Adelman \& Taylor, 2006; Lean \& Colucci, 2010; 2013). This may also provide a reminder that depression and other mental health concerns require effective and high fidelity treatment in order to properly care for students. Additionally, it is possible that other factors that contribute to adolescent depression are not represented in this study. Further research to understand predictors of depression in adolescents would benefit both our understanding of mental health phenomena and our ability to intervene.

Parent support was significantly positively associated with well-being. Parent support was similarly, negatively associated with depression, indicating that parent support both bolsters well-being and ameliorates depression. This seems to be a confirming finding, as parent support intuitively relates to overall mental health, and highlights the importance of these life-long connections for students. The importance of parenting influences are well-established in the literature, including the importance of social support from parents (Sesma et al., 2013; Tatar, 1998; Youngblade et al., 2007). Furstenberg and Hughes (1995) found that emotionally distant 
relationships with parents were associated with negative outcomes at school; this study provides some support for the opposite effect.

Teacher support was also found to be associated with both an increase in well-being and a decrease in depression. Similar to parents, this supports the importance of teacher relationships for adolescents and the fact that positive connections can be protective for mental health. This finding supports other studies that have previously concluded that positive relationships with teachers are an important element of students' mental health (Jennings \& Greenberg, 2009; Murray \& Greenberg, 2000; Yeung \& Leadbeater, 2010; Tatar, 1998). This finding also reflects multiple mentions of students characterizing teachers as important and significant in their lives (Darling et al., 2003; Tatar, 1998).

This study also indicated a positive relationship between community adult support and well-being, and a negative association with depression. Like parent and teacher support, this may indicate that relationships with "other" adults are protective for overall mental health, particularly for well-being. The importance of community adult support in this study again adds to prior research indicating the importance of support from adults that represent multiple layers of a students ecology (Darling et al., 2003; Edwards, Mumford, \& Serra-Roldan, 2007; Hamilton \& Hamilton, 2004; Scales \& Gibbons, 1996; Sesma et al., 2013). This finding may also be important in the context of school climate. While school climate includes relationships with adults and peers (Cohen et al., 2009; De Pedro et al., 2012), other adults in the community are not necessarily included. These outside relationships may improve mental health outcomes for students in combination with or above school-based influences.

One premise of this study is that adults from multiple ecological layers (i.e. home, school, and community) are important for the mental health of adolescents. Our results indicate that 
overall, these different adult relationships do have an influence on adolescent mental health. Each of these ecological layers contributed independently to well-being and depression, indicating that the influence of each group is important, perhaps in combination with the overall constellation of supportive relationships.

In the present study, being male was associated with increased well-being. This is consistent with research that girls are more prone to depressive features especially during adolescence (Kuperminc, Leadbeater, \& Blatt, 2001; Steinberg \& Morris, 2001). However, Scales and Gibbons (1996) noted that girls were likely to have larger networks of non-parent adult resources and may be closer to those adults than boys.

Compared to students in seventh grade, those in ninth and eleventh grade were associated with less well-being and more depression in this sample. It is possible that the transition to and subsequent demands of high school are significant stressors for these adolescents; academic and social experiences become more complicated during this time. Some developmental researchers note that depression often increases in adolescents (Cicchetti \& Toth, 1998; Steinberg \& Morris, 2001). Conversely, others reported that older students have more adult support figures in their lives (Scales \& Gibbons, 1996).

The results of this study regarding ethnicity do not lead to clear conclusions. Previous research has found that that Latino adolescents have more severe mental health needs (e.g. Umana-Taylor \& Updegraff, 2007), and studies often address issues acculturation and discrimination (e.g. Coker et al., 2009). Our results indicated a positive association with wellbeing for Latino students compared to white students, and a positive association with those students reporting mixed race or Asian/American Indian/Pacific Islander/Alaska Native with depression, indicating potentially worse outcomes for these groups. 
There are a few limitations to consider. First, because this study used cross-sectional data, causality cannot be inferred. Second, the independent variables describing parent support available in the data set were qualitatively different than those used for teacher and community adult support. Though using information about the participation of parents is consistent with other studies of student outcomes (Jeynes, 2007; Zellman \& Waterman, 1998), it remains that that fewer details were available about parent support.

\section{Implications and Future Research}

Continued research to strengthen our understanding of student mental health and adult relationships is needed in multiple areas. Future work utilizing longitudinal data or repeated measures would contribute to the understanding of how supportive relationships lead to positive and negative outcomes for youth. This might be particularly important in order to develop a better understanding of specific needs in specific grades. Future studies that could capitalize on consistent measures for all three support groups (i.e. parents, teachers, adults in the community) would be also be useful. It makes sense that these three groups of adults might be important influences for students, and further clarification of distinctive influences might become clear with different data. Additionally, there may be cultural considerations that warrant consideration, especially relating to caregivers at home. It may be that grandparents or other extended family represent important social support for adolescents in addition, or even instead of their parents.

The findings from this study indicate that adult relationships do not influence all aspects of mental health equally. In this sample, adult supportive relationships were more influential on well-being than they were on depression. Cultivation of supportive adult relationships may contribute to the resiliency of students. Social workers in schools and other community-based organizations might consider ways to facilitate or encourage relationships with youth, and even 
identify youth who lack supportive adult relationships and thus target efforts to facilitate adult relationships or mentors. Despite the fact that there seemed to be less influence on depression in our sample, adult supportive relationships still exerted a positive or protective influence.

However, given the high prevalence of mental health issues in schools, and the high need for treatment, social workers and school personnel who suspect depression or other mental health concerns should advocate for assessment and treatment of existing mental health issues. 


\section{References}

Adelman, H. S., \& Taylor, L. (2006). Mental health in schools and public health. Public Health Reports (Washington, D.C.: 1974), 121(3), 294-298.

Benbenishty, R. (2013). Building Capacity in Military-Connected Schools Consortium Technical and Evaluation Report Year 3. Retrieved from http://buildingcapacity.usc.edu/Building\%20Capacity\%20Year\%203\%20Technical\%20Eval uation\%20Report.pdf.

Benbenishty, R., \& Astor, R. A. (2005). School violence in context: Culture, neighborhood, family, school, and gender. Oxford University Press.

Cederbaum, J. A., Gilreath, T. D., Benbenishty, R., Astor, R. A., Pineda, D., DePedro, K. T., et al. (2013). Well-being and suicidal ideation of secondary school students from military families. Journal of Adolescent Health. 54(6), 672-677.

Cicchetti, D., \& Toth, S. L. (1998). The development of depression in children and adolescents. American Psychologist, 53(2), 221-241.

Cohen, J., McCabe, L., Michelli, N. M., \& Pickeral, T. (2009). School climate: Research, policy, practice, and teacher education. The Teachers College Record, 111(1), 180-213.

Coker, T. R., Elliott, M. N., Kanouse, D. E., Grunbaum, J. A., Schwebel, D. C., Gilliland, M. J., ... \& Schuster, M. A. (2009). Perceived racial/ethnic discrimination among fifth-grade students and its association with mental health. American Journal of Public Health, 99(5), 878-884.

Darling, N., Hamilton, S. F. and Shaver, K. H. (2006) Relationships Outside the Family: Unrelated Adults, in Blackwell Handbook of Adolescence (eds G. R. Adams and M. D. Berzonsky), Blackwell Publishing Ltd, Oxford, UK. doi: 10.1002/9780470756607.ch17 
Davis, A. M., Kreutzer, R., Lipsett, M., King, G., \& Shaikh, N. (2006). Asthma prevalence in Hispanic and Asian American ethnic subgroups: Results from the California Healthy Kids Survey. Pediatrics, 118(2), e363-e370.

Davis, A., Lipsett, M., Milet, M., Etherton, M., \& Kreutzer, R. (2007). An association between asthma and BMI in adolescents: Results from the California Healthy Kids Survey. Journal of Asthma, 44(10), 873-879.

Davis, B., \& Carpenter, C. (2009). Proximity of fast-food restaurants to schools and adolescent obesity. Journal Information, 99(3), 505-510.

De Pedro, K. M. T. (2012). The Role of School Climate in the Mental Health and Victimization of Students in Military-connected Schools (Doctoral dissertation, University of Southern California).

Drukker, M., Buka, S. L., Kaplan, C., McKenzie, K., \& Van Os, J. (2005). Social capital and young adolescents' perceived health in different sociocultural settings. Social science \& medicine, 61(1), 185-198.

Edwards, O. W., Mumford, V. E., \& Serra-Roldan, R. (2007). A positive youth development model for students considered at-risk. School Psychology International, 28(1), 29-45.

Estrada, J. N., Gilreath, T. D., Astor, R. A., \& Benbenishty, R. (2013). Gang membership of California middle school students: behaviors and attitudes as mediators of school violence. Health education research. 28 (4), 626-639.

Fraser, M. W. (Ed.). (2004). Risk and resilience in childhood: An ecological perspective. Washington, DC: NASW Press.

Furstenberg Jr, F. F., \& Hughes, M. E. (1995). Social capital and successful development among atrisk youth. Journal of Marriage and the Family, 580-592. 
King, P. E., Dowling, E. M., Mueller, R. A., White, K., Schultz, W., Osborn, P., ... \& Scales, P. C. (2005). Thriving in Adolescence The Voices of Youth-Serving Practitioners, Parents, and Early and Late Adolescents. The Journal of Early Adolescence, 25(1), 94-112.

Gilreath, T. D., Cederbaum, J. A., Astor, R. A., Benbenishty, R., Pineda, D., \& Atuel, H. (2013). Substance use among military-connected youth: The California Healthy Kids Survey. American Journal of Preventive Medicine, 44(2), 150-153.

Hamilton, S. F., \& Hamilton, M. A. (2004). Contexts for mentoring: Adolescent-adult relationships in workplaces and communities. Handbook of adolescent psychology, 2, 395-428.

Hanson, T. L., \& Kim, J. (2007). Measuring resilience and youth development: The psychometric properties of the healthy kids survey. Issues \& Answers Report, REL, (034).

Jennings, G. (2003). An exploration of meaningful participation and caring relationships as contexts for school engagement. The California School Psychologist, 8, 43-52.

Jennings, P. A., \& Greenberg, M. T. (2009). The prosocial classroom: Teacher social and emotional competence in relation to student and classroom outcomes. Review of educational research, $79(1), 491-525$.

Jeynes, W. H. (2007). The Relationship Between Parental Involvement and Urban Secondary School Student Academic Achievement A Meta-Analysis.Urban education, 42(1), 82-110.

Kessler, R. C., Andrews, G., Colpe, L. J., Hiripi, E., Mroczek, D. K., Normand, S. L. T., ... \& Zaslavsky, A. M. (2002). Short screening scales to monitor population prevalences and trends in non-specific psychological distress. Psychological medicine, 32(6), 959-976.

Kim, J., \& McCarthy, W. J. (2006). School-level contextual influences on smoking and drinking among Asian and Pacific Islander adolescents. Drug and Alcohol Dependence, 84(1), 56-68. 
Lakey, B., \& Cohen, S. (2000). Social support theory and measurement. Social support measurement and intervention: A guide for health and social scientists, 29-52.

Lean, D. S., \& Colucci, V. A. (2010). School-based mental health: Framework for intervention R\&L Education.

Lean, D., \& Colucci, V. A. (2013). School-based Mental Health: A Framework for Intervention. R\&L Education.

Murray, C., \& Greenberg, M. T. (2000). Children's relationship with teachers and bonds with school an investigation of patterns and correlates in middle childhood. Journal of School Psychology, 38(5), 423-445.

O'Brennan, L. M., \& Furlong, M. J. (2010). Relations between students' perceptions of school connectedness and peer victimization. Journal of School Violence, 9(4), 375-391.

Pinkerton, J., \& Dolan, P. (2007). Family support, social capital, resilience and adolescent coping. Child \& family social work, 12(3), 219-228.

Richman, J. M., Bowen, G. L., \& Woolley, M. E. (2004). School failure: An eco-interactional developmental perspective. In M. Fraser (Ed.), Risk and Resilience in Childhood: An ecological perspective (133-160). Washington DC: NASW Press.

Sallis, J. F., Owen, N., \& Fisher, E. B. (2008). Ecological models of health behavior. Health behavior and health education: Theory, research, and practice, 4, 465-486.

Scales, P. C., \& Gibbons, J. L. (1996). Extended family members and unrelated adults in the lives of young adolescents: A research agenda." Journal of Early Adolescence, 16(4), 365-389. doi: $10.1177 / 0272431696016004001$

Scales, P. C., Benson, P. L., \& Roehlkepartain, E. C. (2011). Adolescent thriving: The role of sparks, relationships, and empowerment. Journal of Youth and Adolescence, 40, 263-277. 
Scales, P. C., Benson, P. L., Roehlkepartain, E. C., Sesma Jr, A., \& van Dulmen, M. (2006). The role of developmental assets in predicting academic achievement: A longitudinal study. Journal of adolescence, 29(5), 691-708.

Sesma Jr, A., Mannes, M., \& Scales, P. C. (2013). Positive adaptation, resilience and the developmental assets framework. Handbook of resilience in children (pp. 427-442) Springer.

Sharkey, J. D., You, S., \& Schnoebelen, K. (2008). Relations among school assets, individual resilience, and student engagement for youth grouped by level of family functioning. Psychology in the Schools, 45(5), 402-418.

Smith, J., Wohlstetter, P., Kuzin, C. A., \& De Pedro, K. (2011). Parent Involvement in Urban Charter Schools: New Strategies for Increasing Participation. School Community Journal, 21(1), 71-94.

Steinberg, L., \& Morris, A. S. (2001). Adolescent development. Journal of Cognitive Education and Psychology, 2(1), 55-87.Tatar, M. (1998). Significant individuals in adolescence: Adolescent and adult perspectives. Journal of Adolescence, 21(6), 691-702.

Umaña-Taylor, A. J., \& Updegraff, K. A. (2007). Latino adolescents' mental health: Exploring the interrelations among discrimination, ethnic identity, cultural orientation, self-esteem, and depressive symptoms. Journal of Adolescence, 30(4), 549-567.

Watson, D., \& Clark, L. A. (1999). The PANAS-X: Manual for the positive and negative affect schedule-expanded form. Available at: http://www.psychology.uiowa.edu/faculty/clark/panas-x.pdf. Accessed March 23, 2014. 
Wong, M. M., Klingle, R. S., \& Price, R. K. (2004). Alcohol, tobacco, and other drug use among Asian American and Pacific Islander adolescents in California and Hawaii. Addictive Behaviors, 29(1), 127-141.

Yeung, R., \& Leadbeater, B. (2010). Adults make a difference: the protective effects of parent and teacher emotional support on emotional and behavioral problems of peer-victimized adolescents. Journal of Community Psychology, 38(1), 80-98.

Youngblade, L. M., Theokas, C., Schulenberg, J., Curry, L., Huang, I. C., \& Novak, M. (2007). Risk and promotive factors in families, schools, and communities: A contextual model of positive youth development in adolescence. Pediatrics, 119(Supplement 1), S47-S53.

Zellman, G. L., \& Waterman, J. M. (1998). Understanding the impact of parent school involvement on children's educational outcomes. The Journal of Educational Research, 91(6), 370-380. 